\title{
My Skinny Sister
}

\section{Eberhard Wolff}

PD Dr. rer. soc., Redaktor Kultur, Geschichte, Gesellschaft

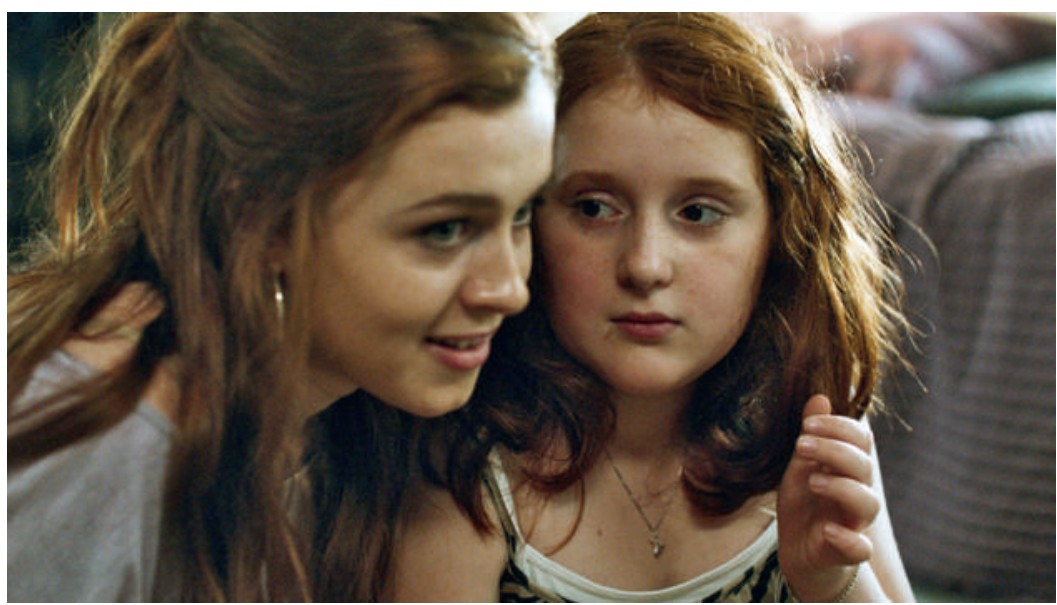

Die schöne grosse Schwester - zum Beneiden.

Stella ist zwölf. Sie bewundert ihre 16-jährige Schwester Katja, eine erfolgreiche Eiskunstläuferin. Da kann Stella nicht mithalten, ist neidisch, versucht selber Eiskunstlauf, scheitert und zweifelt an sich selbst. Sie hat Angst, einen Schnurrbart zu bekommen, und liebt Katjas Eislauflehrer. Probleme mitten in der frühen Pubertät. So, wie wir es kennen.

Die grosse Schwester Katja hat Stress. Katja trainiert und trainiert. Sie isst keine Chips, und heimlich dann doch, rastet immer wieder aus. Und zickt. Katja steckt sich den Finger in den Hals. Stella merkt das, Katja zwingt sie aber zum Schweigen. Schliesslich kann Katja

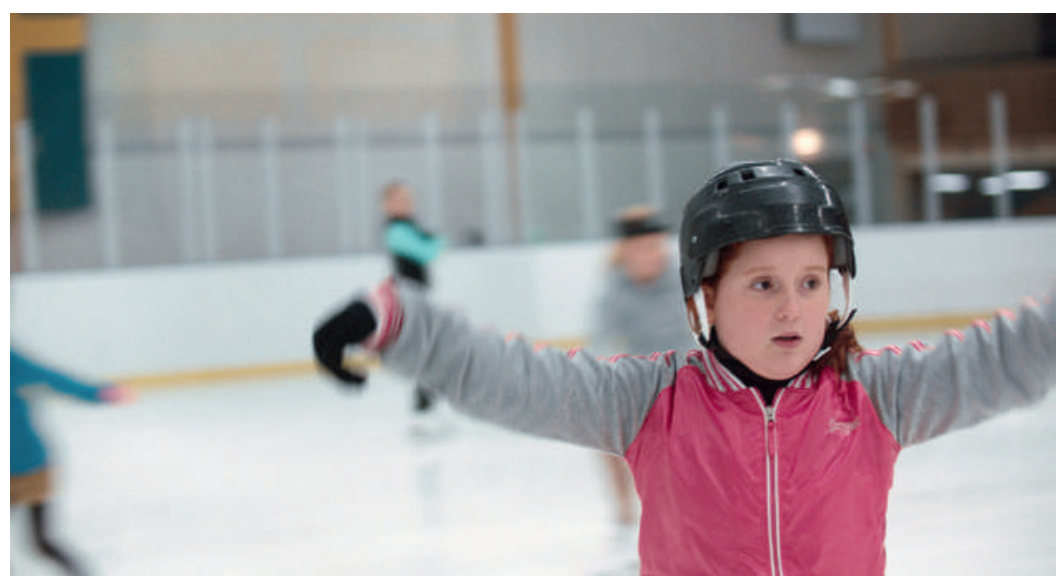

Eislaufen kann die grosse Schwester auch besser... überhaupt nichts mehr essen und wird magersüchtig. Probleme des jungen Erwachsenseins. So, wie wir es immer wieder sehen.

Die Eltern wollen die Familie zusammen- und über Wasser halten. Sie tun ihr Bestes, aber das reicht nicht. Im Ferienhaus eskaliert die Angelegenheit. Die Eltern wollen Katja helfen, sind am Ende überfordert und rasten aus. Stella wird an den Rand gedrückt.

Was wie ein unanmächeliger "Problemfilm» tönt, ist eine wunderschöne Filmgeschichte, ruhig und eindrucksvoll, feinfühlig, offen, ohne vordergründige Moral und dadurch so wertvoll. Der Film von Sanna Lenken ist liebevoll-realistisch aus dem Alltag heraus gefilmt wie viele neuere schwedische Produktionen, nicht zuletzt einige Krimiserien; in schönen, eher kühlen Bildern choreographiert und vertont. Selten sind Lachszenen so befreiend verfilmt worden.

Das Highlight ist die kleine Schwester Stella. Sie beobachtet den aufkommenden Sturm, macht sich ihren Reim darauf, sagt ihre Meinung. Und immer tiefer steckt sie mitten drin im Sturm, leidet, fühlt sich schuldig, wird wütend - wie im richtigen Leben. Aber sie ist da, wenn es schwierig wird, und macht den Mund auf, wenn es nötig ist. Die Kleinste wird zum Scharnier der Familie und hilft allen aus dem Sturm heraus. Eine grandiose Leistung der jungen Schauspielerin Rebecka Josephson in ihrem ersten Film.

Die Film-Stella wächst am Ende an all diesen Herausforderungen. Echte Kinder könnten daran zerbrechen. Der Film sei wärmstens empfohlen für Jugendliche, Eltern, Geschwister, Freundinnen, Lehrer, Betreuer, Therapeuten aller Couleur, auch Ärzte, Ökotrophologen und alle entsprechenden «-innen» - sowie Menschen, die gutes Kino lieben.

Achtung Spoiler: Am Ende stehen eine Klinik, eine Freundschaft, eine existierende Familie, eine Romreise für Stella und eine Hoffnung am Horizont. Und nicht zuletzt ein Eindruck von der wichtigen Rolle von Kindern im Familiengefüge.

Der Film My Skinny Sister läuft seit Anfang November in verschiedenen Schweizer Kinos. 